\title{
Cheese peptidomics: A detailed study on the evolution of the oligopeptide fraction in Parmigiano-Reggiano cheese from curd to 24 months of aging
}

\author{
S. Sforza, ${ }^{1}$ V. Cavatorta, F. Lambertini, G. Galaverna, A. Dossena, and R. Marchelli \\ Department of Organic and Industrial Chemistry, University of Parma, Viale delle Scienze 17a, University Campus, I-43124, Parma, Italy
}

\section{ABSTRACT}

In this work, we performed a detailed evaluation of the evolution of the oligopeptide fractions in samples of Parmigiano-Reggiano cheese from the curd up to 24 mo of aging. The samples were taken from wheels produced the same day, in the same factory, from the same milk, during the same caseification process, thus simplifying the natural variability of a whey-based starter fermentation. This unique and homogeneous sampling plan, never reported before in the literature, provided a detailed study of the peptides produced by enzymatic events during Parmigiano-Reggiano aging. Given the large dimensions of the $35-\mathrm{kg}$ wheels of ParmigianoReggiano, samples were taken from both the internal and external parts of the cheese, to evidence eventual differences in the oligopeptide composition of the different parts. Fifty-seven peptides were considered, being among the most abundant during at least one of the periods of ripening considered, and their semiquantification indicated that the peptide fraction of ParmigianoReggiano cheese constantly evolves during the aging period. Five trends in its evolution were outlined, which could be clearly correlated to the enzymatic activities present in the cheese, making it possible to discriminate cheeses according to their aging time. Several known bioactive peptides were also found to be present in Parmigiano-Reggiano cheese samples, and for the first time, the age at which they are most abundant has been identified. Aged cheeses have been shown to be dominated by nonproteolytic aminoacyl derivatives, a new class of peptide-like molecules recently reported. Finally, the changing peptide pattern may be related to the changing enzymatic activities occurring inside the cheeses during the aging period, which, in turn, are also related to the microbiological composition.

Key words: cheese peptidomics, peptide fraction, proteolysis, Parmigiano-Reggiano

Received October 13, 2011.

Accepted February 24, 2012

${ }^{1}$ Corresponding author: stefano.sforza@unipr.it

\section{INTRODUCTION}

The most complex and most important biochemical event taking place during cheese production and maturation is undoubtedly proteolysis (McSweeney, 2004); it contributes to cheese softening by breaking down milk proteins, it decreases the water activity through water binding by increasing the free carboxylic and amino groups, and it contributes to flavor development directly (through the release of mostly bitter peptides and AA) and indirectly by producing substrates for other biochemical reactions (such as AA deamination and decarboxylation). Proteolysis is due to enzymatic activities originating from various sources: residual coagulant activity; proteolytic enzymes originally present in milk, produced from starter lactic acid bacteria (LAB) and nonstarter LAB (NSLAB); and, in several cheeses, from secondary flora or exogenous enzymes added to accelerate ripening (Sousa et al., 2001). As a general scheme of proteolysis in cheeses, caseins are initially hydrolyzed by curd and milk proteolytic enzymes to large- and intermediate-size peptides, which, in turn, are hydrolyzed by LAB and NSLAB proteinases and peptidases to short peptides and AA (Piraino et al., 2007).

Parmigiano-Reggiano is a well-known Italian hard cheese, long ripened, made from raw and partly skimmed cow milk with added natural whey starter. It is included in the list of Italian cheeses bearing the protected designation of origin (PDO, EU regulation 2081/92). This definition includes technological characteristics and geographic restrictions. The production of milk and its transformation into cheese can take place only in the northern Italian provinces of Parma, Reggio Emilia, Modena, and in some parts of Bologna and Mantova. Cows have to be fed only grass or hay and are reared following specific breeding techniques. Despite this local production, Parmigiano-Reggiano is widespread and consumed all over the world.

Several papers have reported the composition of the oligopeptide fraction of Parmigiano-Reggiano (Addeo at al., 1992, 1994; Sforza et al., 2004) and similar hard cheeses (Ferranti et al., 1997a,b; Sforza et al., 2003). However, a detailed picture of the evolution of such a 
complex fraction during the aging period is still lacking, as is a clear indication of the most abundant peptides at various months of aging. Such knowledge might be extremely useful to gain insights into the action of the different proteolytic systems involved in ParmigianoReggiano cheese maturation, as the enzymatic activity determined in cheese extracts might not be coincident with the actual activity in real cheeses. The identification of the most abundant proteolytic products at different aging times could give direct indication about the enzymes active in the cheese and on their dynamics. Moreover, the identified oligopeptides, being related to the enzymatic activity (which, in turn, is related to the milk, technology, microbiota, and time of aging), could be used as molecular markers for assessing all of these parameters. In addition, information lacking in the existing literature, and of primary importance for large-dimension cheeses, is the distribution of peptides inside the wheels, going from the external part, close to the rind, to the internal part, close to the center.

These studies are usually hampered by the huge variability existing among cheeses supposedly of the same type, but produced by different factories, with different milk batches, at different times of the year, with variable starters. Moreover, many studies are mostly focused only on the identification of the peptide sequences, without attempting to characterize quantitative or at least semiquantitative trends of the various peptides.

In this work, we performed a detailed evaluation of the oligopeptide fraction of samples of Parmigiano-Reggiano from the curd up to 24 mo of aging. To decrease the natural variability, the samples were taken from wheels of Parmigiano-Reggiano cheese produced on the same day, in the same factory, from the same milk, during the same caseification process. These homogeneous wheels provided a unique sampling plan, never reported before in the literature, to study the peptides produced by the enzymatic events occurring in Parmigiano-Reggiano cheese during aging. Given the large dimensions of the wheels of Parmigiano-Reggiano (diameter 35-45 $\mathrm{cm}$, height $18-24 \mathrm{~cm}$, weight $35-40 \mathrm{~kg}$ ), samples were always taken both from the internal and the external part of the wheels, to evidence eventual differences in the oligopeptide composition. Semiquantification was carried out by liquid chromatography (LC)/electrospray ionization (ESI)-MS analysis using a suitable internal standard.

\section{MATERIALS AND METHODS}

\section{Samples}

Cheese samples were obtained from the Consorzio del Parmigiano-Reggiano (Reggio Emilia, Italy). Samples were taken from the curd, 12 and $48 \mathrm{~h}$ after precipitation, immediately after brining ( 1 mo of aging) and after $2,3,4,6,8,10,12,16,20$, and 24 mo. All of the cheese samples were obtained during the 2 yr of ripening, starting from cheeses prepared on the same day, in the same factory, and using the same batch of milk. Cheese production was performed according to the Consortium of Parmigiano-Reggiano. Briefly, the milk of the day before, which spontaneously surfaced the fat fraction, was mixed with fresh milk in copper vats. Calf rennet and whey coming from the cheese production of the day before, naturally rich in starter LAB, were added. Although the whey starter microbiota may vary among dairy factories, it is usually mainly composed of thermophilic strains of Lactobacillus helveticus (Bottari et al., 2010). The curd was broken and heated at $55^{\circ} \mathrm{C}$ for about $50 \mathrm{~min}$. At this point, the curd was extracted and placed in a mold at room temperature $\left(\sim 20^{\circ} \mathrm{C}\right)$ and then, after few days, immersed in brine. After $1 \mathrm{mo}$, the wheels were extracted, washed, and the aging period started. At each sampling time (except in the case of the curd), the wheels were sampled from a horizontal section in 2 different zones: external (from the rind up to $6 \mathrm{~cm}$ from the rind) and internal (from $7 \mathrm{~cm}$ from the rind up to the center part of the wheel). At each sampling time, the cheese was grated and kept at $-20^{\circ} \mathrm{C}$ until the analyses were performed (usually within a few days). The water content, sodium chloride content, and $\mathrm{pH}$ of the samples were provided by the Consorzio of Parmigiano-Reggiano. The water content was always found to be different between the internal and the external part of the wheels, being 1 to $3 \%$ higher in the former part. At the end of the aging time (24 mo), the humidity values were, respectively, 33 and $30 \%$. Sodium chloride content, due to the immersion in brine, was initially higher in the external part, with values around $1.2 \%$ after 10 mo. Then, due to the slow diffusion toward the internal part and water evaporation, slightly higher but homogeneous values were reached at the end of the aging time; at $24 \mathrm{mo}$, the sodium chloride content was $1.4 \%$ both for the internal and the external part. The $\mathrm{pH}$ was found to be 5.1 in the external part after $12 \mathrm{~h}$, whereas the same value was reached in the internal part only after $48 \mathrm{~h}$. After 4 mo, the $\mathrm{pH}$ values were homogeneous throughout the wheel (around 5.35) and at the end of aging (at $24 \mathrm{mo}$ ), the $\mathrm{pH}$ value was around 5.4.

\section{Extraction and Concentration of the Oligopeptide Fraction}

Ten grams of finely grated cheese was suspended in $45 \mathrm{~mL}$ of $0.1 \mathrm{~N} \mathrm{HCl}$. (L,L)-Phenylalanylphenylalanine (Phe-Phe) was added as an internal standard $(2.5 \mathrm{~mL}$ 
of a $1 \mathrm{~m} M$ solution). The suspension was homogenized for 1 min using an Ultra-Turrax homogenizer (IKAWerke GmbH \& Co. KG, Staufen, Germany) and then centrifuged at $3,400 \times g$ for $40 \mathrm{~min}$ at $4^{\circ} \mathrm{C}$. The solution was filtered through paper filters and extracted 3 times with $40 \mathrm{~mL}$ of ethyl ether. The aqueous solution was filtered through a $0.45-\mu \mathrm{m}$ filter. A total of $3 \mathrm{~mL}$ of the resulting solution was dried and redissolved in $900 \mu \mathrm{L}$ of a $0.1 \%$ formic acid solution ( $\mathrm{pH} 3)$. The solution was diafiltered through poly(lactide-co-glycolide-co-caprolactone) (PLGC) filters with nominal molecular cut-off at $10 \mathrm{kDa}$ at 2,800 $\times \mathrm{g}$ using an Amicon Micropartition system MPS-1 (Millipore Corp., Billerica, MA). The filtrate was dried under nitrogen, redissolved in $500 \mu \mathrm{L}$ of $0.1 \% \mathrm{HCOOH}$ in $\mathrm{H}_{2} \mathrm{O}$, and analyzed by HPLC/MS. Each sample was extracted and analyzed in triplicate.

\section{LC/ESI-MS Analysis of the Oligopeptide Fraction}

The LC/ESI-MS analysis was carried out on an Alliance 2695 separation module interfaced with an Acquity SQD MS system (Waters Corp., Milford, MA) with a $\mathrm{C}_{18}$ column $(5 \mu \mathrm{m}, 300 \AA$, $250 \times 4.6 \mathrm{~mm}$, Jupiter; Phenomenex Inc., Torrance, CA). Eluent $\mathrm{A}$ was $\mathrm{H}_{2} \mathrm{O}$ $\left(0.2 \% \mathrm{CH}_{3} \mathrm{CN}\right.$ and $\left.0.1 \% \mathrm{HCOOH}\right)$ and eluent $\mathrm{B}$ was $\mathrm{CH}_{3} \mathrm{CN}\left(0.2 \% \mathrm{H}_{2} \mathrm{O}\right.$ and $\left.0.1 \% \mathrm{HCOOH}\right)$. Gradient conditions were as follows: 0 to $15 \mathrm{~min}$ : isocratic $100 \% \mathrm{~A}$; 15 to 60 min: linear gradient from $100 \%$ A to $67 \%$ A; 60 to $69 \mathrm{~min}$ : isocratic $67 \% \mathrm{~A} ; 69$ to $70 \mathrm{~min}$ : from 67 to $60 \% \mathrm{~A} ; 70$ to $80 \mathrm{~min}$ : from $60 \% \mathrm{~A}$ to $0 \% \mathrm{~A} ; 80$ to $85 \mathrm{~min}$ : isocratic $0 \% \mathrm{~A}$; and reconditioning. The flow rate was $1 \mathrm{~mL} / \mathrm{min}$. The MS conditions were as follows: ESI interface with $90 \%$ splitting of the column flow, positive ions; capillary voltage: $3.2 \mathrm{kV}$; cone voltage: 30 $\mathrm{V}$; source temperature: $100^{\circ} \mathrm{C}$; desolvation temperature: $150^{\circ} \mathrm{C}$; cone gas $\left(\mathrm{N}_{2}\right): 100 \mathrm{~L} / \mathrm{h}$; desolvation gas $\left(\mathrm{N}_{2}\right)$ : $450 \mathrm{~L} / \mathrm{h}$; acquisition in total ion mode (TIC, 100-1,900 $\mathrm{m} / \mathrm{z}$ ); and scan time: $3 \mathrm{~s}$.

\section{Data Analysis}

The LC/ESI-MS analysis of the extracted fractions was performed (full-scan acquisition). Each LC-MS chromatogram was elaborated, determining characteristic ions, molecular weights, retention times, and insource collision-induced dissociation (CID) fragments (if present) of the main peaks. The molecular weight determination was confirmed by Max Ent application of MassLynx Software (Waters Corp.) in the case of molecular weights higher than 1,000 Da.

Integration of the area of each peptide was performed in an automatic way by QuanLynx software (Waters Corp.), after extraction of the peptide characteristic ion current [extract ion chromatogram (XIC) technique].
Integration parameters included automatic ApexTrack Peak Integration and Noise measurement; smoothing parameters: \pm 1 scan and 1 smoothing by the mean method. The integrated areas of each peptide in each sample were determined, and every peptide was semiquantified by dividing by the area of Phe-Phe (internal standard) in the same sample (semiquantification value $=$ Area $_{\text {peptide }}$ (Area Phe-Phe $_{\text {e }}$. A correction was performed to take into account the water content percentage (W) of every sample [corrected value $=$ semiquantification value $\times(100 /(100-\mathrm{W})]$.

\section{RESULTS AND DISCUSSION}

\section{Identification of the Molecular Mass of the Most Abundant Peptides and Relative Quantification}

Fourteen samples of Parmigiano-Reggiano at different aging times, from the curd up to mo 24 of aging, were obtained, and wheels were sampled externally and internally, as described in the experimental section. The water content of the samples was found to be different

The oligopeptide fractions obtained from the 14 samples of Parmigiano-Reggiano cheeses were extracted by acidic extraction, filtration, and ultrafiltration and analyzed by reversed-phase LC/ESI-MS according to the methods reported in the literature (Sforza et al., 2003, 2004; details in the experimental section). An example of a full-scan chromatogram is shown in Figure 1a.

Molecular masses of the most abundant peptides were obtained by analyzing the mass spectra associated to the most intense chromatographic peaks. More than 100 different peptides were first considered in the preliminary screening, with molecular masses ranging from about 200 to more than 7,000 Da.

Every peptide was then semiquantified in all of the samples against the internal standard Phe-Phe according to a method previously reported (Sforza et al., 2003). The XIC for each peptide was obtained by extracting its characteristic ions (listed in the Supplementary Material, available online at http://www. journalofdairyscience.org/). A typical XIC is shown in Figure 1b.

\section{Identification of the Peptide Fingerprint}

To focus on the most abundant peptides present in the fractions, only peptides that gave a minimum chromatographic signal corresponding to the $20 \%$ of the signal of the internal standard in at least one sample were considered for sequence identification. Thus, starting from the original set of more than 100 peptides, 57 peptides satisfied this requirement and were selected for sequence analysis according to methodol- 
a)

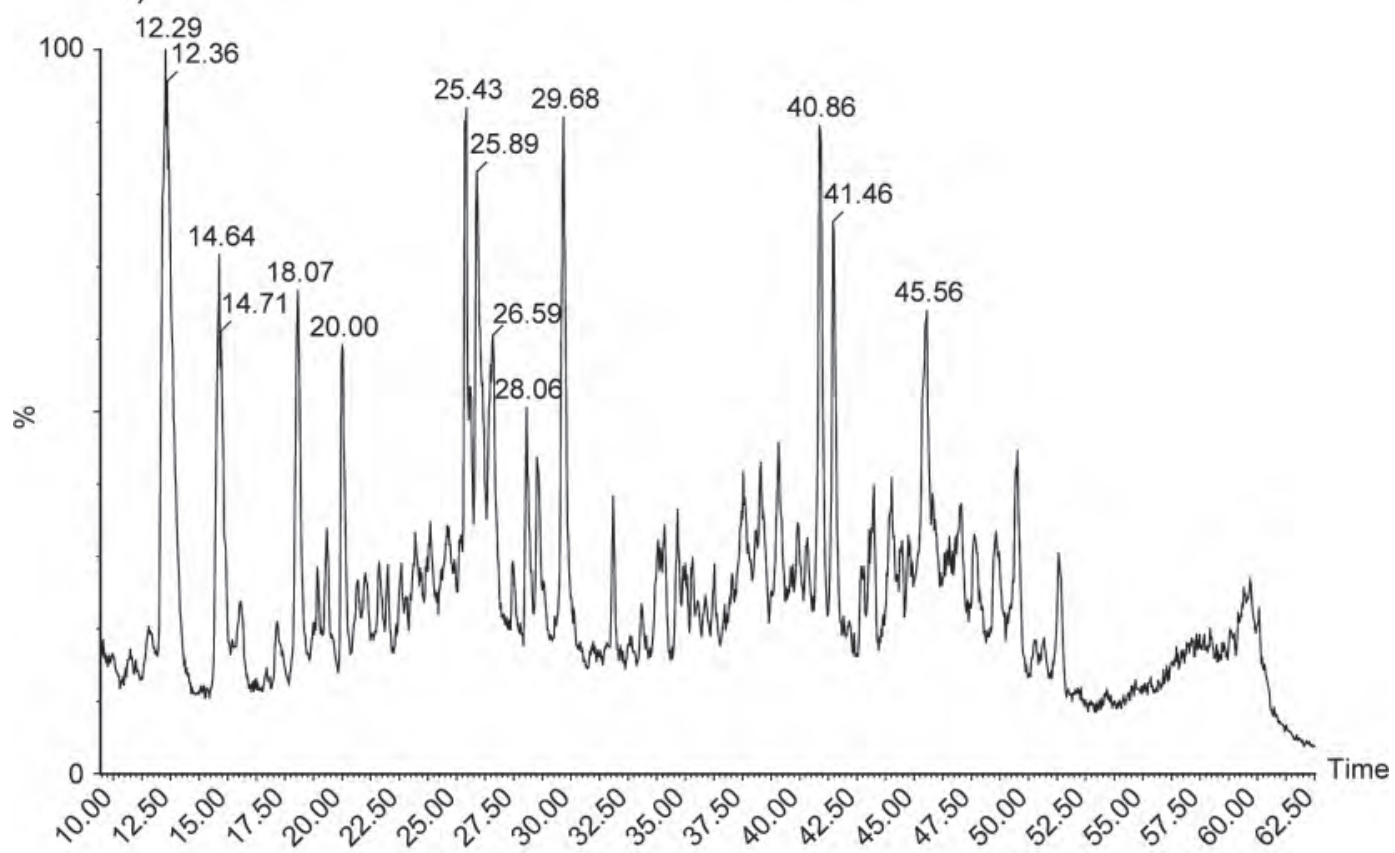

b)

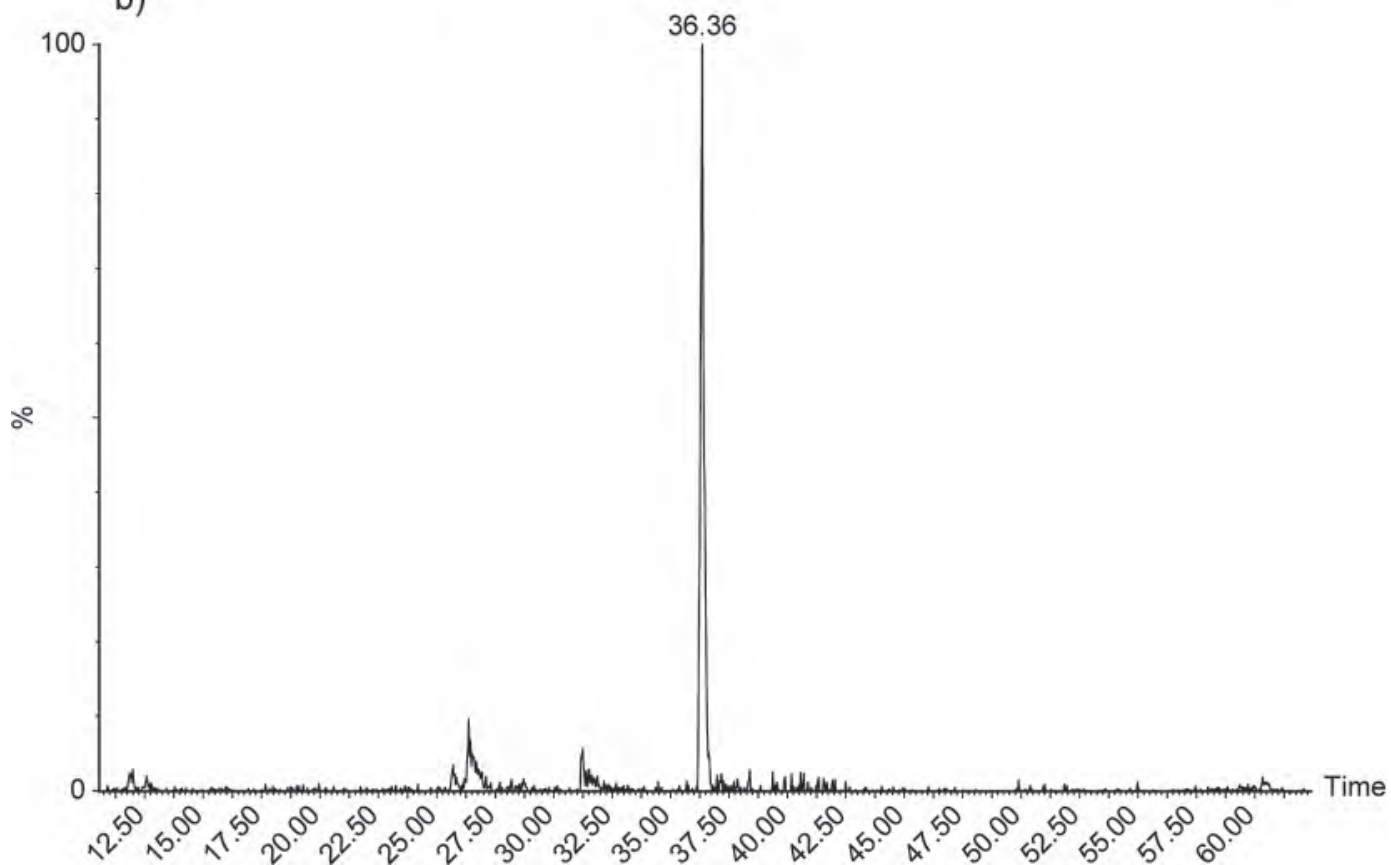

Figure 1. Full-scan chromatogram (a) of the peptide fraction extracted from a Parmigiano-Reggiano cheese aged 24 mo. The extract ion chromatogram (b) was derived from the same chromatogram by extracting the characteristic ions of the peptide $\alpha_{\mathrm{s} 1} \mathrm{CN}(1-23)$. The $\mathrm{x}$-axes indicate retention time in minutes.

ogy previously reported (Sforza et al., 2003) by using originally developed software (S. Sforza, unpublished). Chromatographic considerations on peptide polarity helped in the assessment of a few ambiguous cases. This procedure allowed rapid identification of the sequence of 53 peptides (93\%), which could be considered the peptide fingerprint of Parmigiano-Reggiano cheese. The complete peptide list, together with the diagnostic fragments, are reported in the Supplementary Material (available online at http://www.journalofdairyscience. 
org/), including the relative semiquantitative data in every sample.

Among these peptides, 12 were nonproteolytic aminoacyl derivatives (NPAD); namely, N- $\gamma$-glutamyl-amino acids and N-lactoyl-amino acids, recently identified in Parmigiano-Reggiano and other cheeses.(Sforza et al., 2009; Toelstede et al., 2009) Among the remaining peptides, 17 were found to be generated by proteolytic events from $\alpha_{\mathrm{s} 1}-\mathrm{CN}$ and 24 from $\beta$-CN, consistent with the fact that $\alpha_{\mathrm{s} 1^{-}}$and $\beta-\mathrm{CN}$ together constitute $80 \%$ of the total casein content.

\section{Different Evolutive Trends of the Peptide Fraction During Aging}

It was immediately apparent from the semiquantitative data that no peptide was present in a constant amount during the aging period, but every peptide reached a maximum and a minimum amount at different aging times, with characteristic trends. This finding underlies the evolutive character of the oligopeptide fraction in cheeses and the enzymatic activities throughout the aging period, leading to continuous changes in its composition.

Principal component analysis (PCA) was performed using as variables the semiquantitative data for all peptides. The loading plot and the score plot of the PCA are reported in Figure 2, showing that samples cluster according to their respective aging times and that every aging time is characterized by a different peptide composition.

Peptides could be clustered, according to similar evolutive trends during the aging period, into 5 groups. To the first group belonged peptides that had the maximum amount in the curd, and were then characterized by a constant decrease during the aging period. The sum of the semiquantitative values of these peptides are shown in Figure 3, separately considering the first hours after curding (Figure 3a) and the rest of the aging time up to mo 24 (Figure $3 \mathrm{~b}$ ). The trends were separately considered for the internal and the external part of the wheels. The peptides belonging to this group, listed in decreasing order of the intensity of the chromatographic signal, are also reported (Figure 3c). Several peptides in this group came from the cleavage between positions 23 and 24 of $\alpha_{\mathrm{s} 1}-\mathrm{CN}$, the most abundant being $\alpha_{\mathrm{s} 1}-\mathrm{CN}$ (1-23), or were long peptides coming from the central part of $\beta$-CN. These data indicate that these peptides were mainly produced by the action of rennet enzymes (chymosin, the most abundant enzyme, is known to cleave $\alpha_{\mathrm{s} 1}$-CN at position 23-24; McSweeney et al., 1993). The decreasing trend was a clear indication that these peptides were rapidly degraded during the first hours after curding and up to the first months by the cell envelope proteinases (CEP) of LAB present in the starter culture. It is significant, from this point of view, that the decreasing trend was faster in the external part of the wheel. Curd is cooked at 54 to $55^{\circ} \mathrm{C}$ and, given the dimensions of the Parmigiano-Reggiano wheels, , a considerable difference in temperature remains between the central part and the outer part in the first hours after curding. Consequently, bacterial proliferation is slow in the internal part and faster in the outer part (Fox, 1999) and subsequently a more rapid degradation of the peptides present in the curd takes place in the external part of the wheels.

The second group included peptides that started to increase in the first hours after curding but reached the maximum amount around mo 1 to 2 of aging, and then were characterized by a constant decrease, leveling off at mo 10 of aging, keeping constant at low values. Trends for the second group and the peptide list are shown in Figure 4. This group was mainly characterized by small peptides, many of them coming from proteolysis of the peptides belonging to the previous group: $\alpha_{\mathrm{s} 1} \mathrm{CNf}(17-23), \quad \alpha_{\mathrm{s} 1} \mathrm{CNf}(16-20)$, $\alpha_{\mathrm{s} 1} \mathrm{CNf}(1-17), \quad \alpha_{\mathrm{s} 1} \mathrm{CNf}(1-13)$, and $\alpha_{\mathrm{s} 1} \mathrm{CNf}(10-16)$ are all part of $\alpha_{\mathrm{s} 1} \mathrm{CNf}(1-23) ; \alpha_{\mathrm{s} 1} \operatorname{CNf}(24-30)$ derives from $\alpha_{\mathrm{s} 1} \mathrm{CNf}(24-34), \quad \alpha_{\mathrm{s} 1} \mathrm{CNf}(24-36)$, and $\alpha_{\mathrm{s} 1} \operatorname{CNf}(24-38)$; $\beta \mathrm{CNf}(103-119)$ is part of the long peptide deriving from the central part of $\beta-\mathrm{CN}$. New peptides also emerged, deriving from the N-terminal part of $\beta-\mathrm{CN}$ $[\beta \operatorname{CNf}(1-6)$ and $\beta \operatorname{CNf}(7-29) 4 \mathrm{P}]$. All of these features suggest that the previously shown peptides of the first group became substrates of proteases, which produced the shorter peptides of this second group. The proteases involved are those produced by LAB, as indicated by the cleavage sites [positions $9-10,13-14,16-17$, and 17-18 of $\alpha_{\mathrm{s} 1}-\mathrm{CN}$, well-known cleavage sites for lactic acid bacteria (Jensen et al., 2009)]. Although peptide $\beta \mathrm{CNf}(193-209)$ is also known to be produced by LAB proteases (Fox and McSweeney, 1996; Broadbent et al., 1998) other than chymosin (Jensen et al., 2009), it is very likely that chymosin itself is responsible for its production. The fact that this peptide is not formed during the early stage of cheese production is probably due to the higher affinity of chymosin for bond 23-24 of $\alpha_{\mathrm{s} 1}-\mathrm{CN}$, preventing action on bond $192-193$ of $\beta-\mathrm{CN}$; only when all of the $\alpha_{\mathrm{s} 1}$-CN has been hydrolyzed, can the action of chymosin on $\beta-\mathrm{CN}$ take place.

Another characteristic that indicated bacterial action in the production of these peptides is that, mirroring what has been shown in Figure 3, they increase more and faster in the outer part of the wheels, where bacterial proliferation in the first hours after curding is expected to be higher. After mo 2 of aging (and, again, starting from the outer part of the wheel), the amount of these peptides started to decrease, probably 

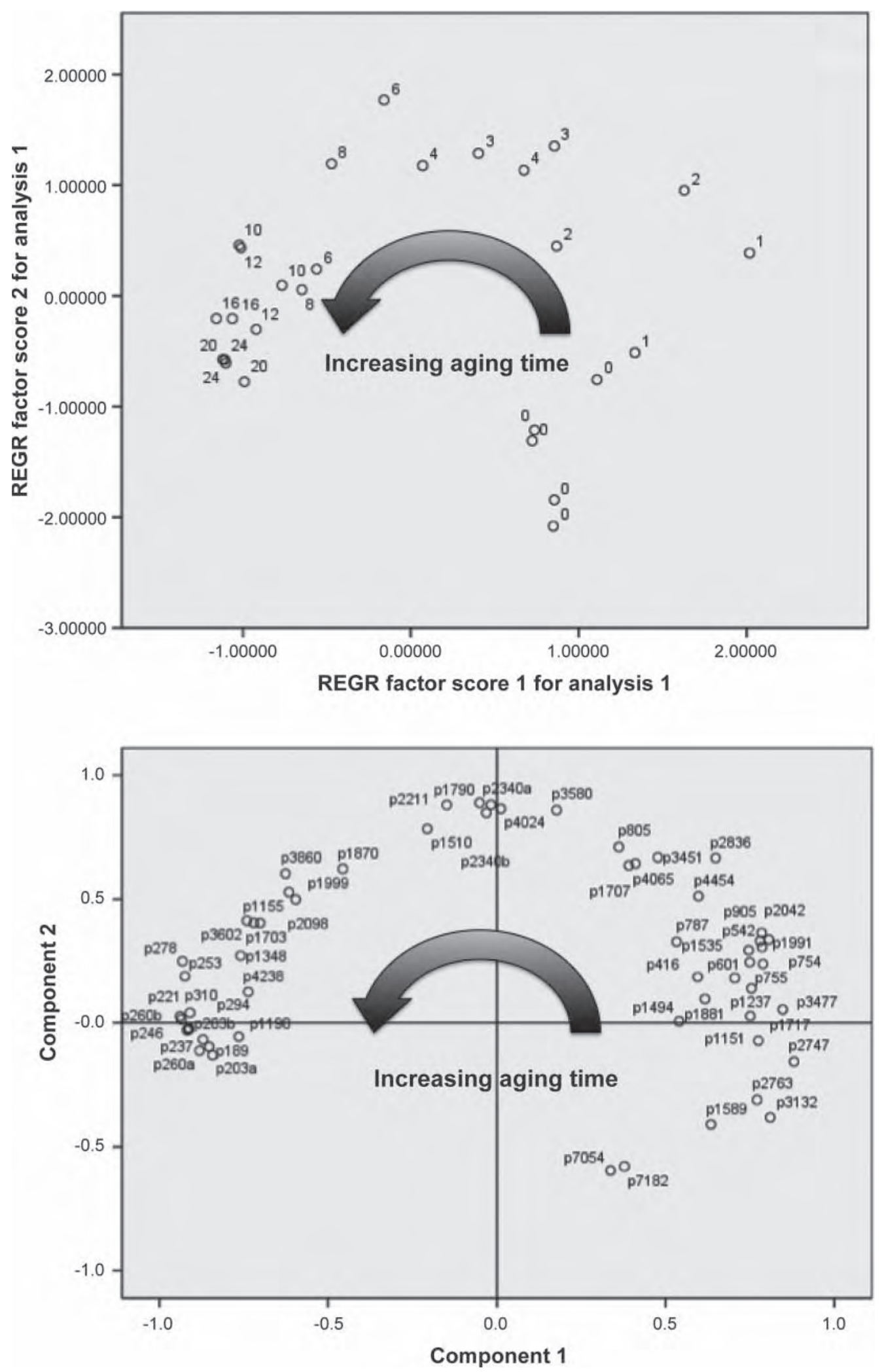

Figure 2. Score plot (top) and loading plot (bottom) of the principal component (PC) analysis done on the samples analyzed by using the peptide semiquantitative data as variables (samples are indicated by the respective month of aging and peptides are indicated according to their molecular mass). Arrows indicate the increasing aging time and show that every different aging time is characterized by different peptides. Variance explained: PC1 47.6\%, PC2: 20.4\% (total variance explained: $68.0 \%$ ). 

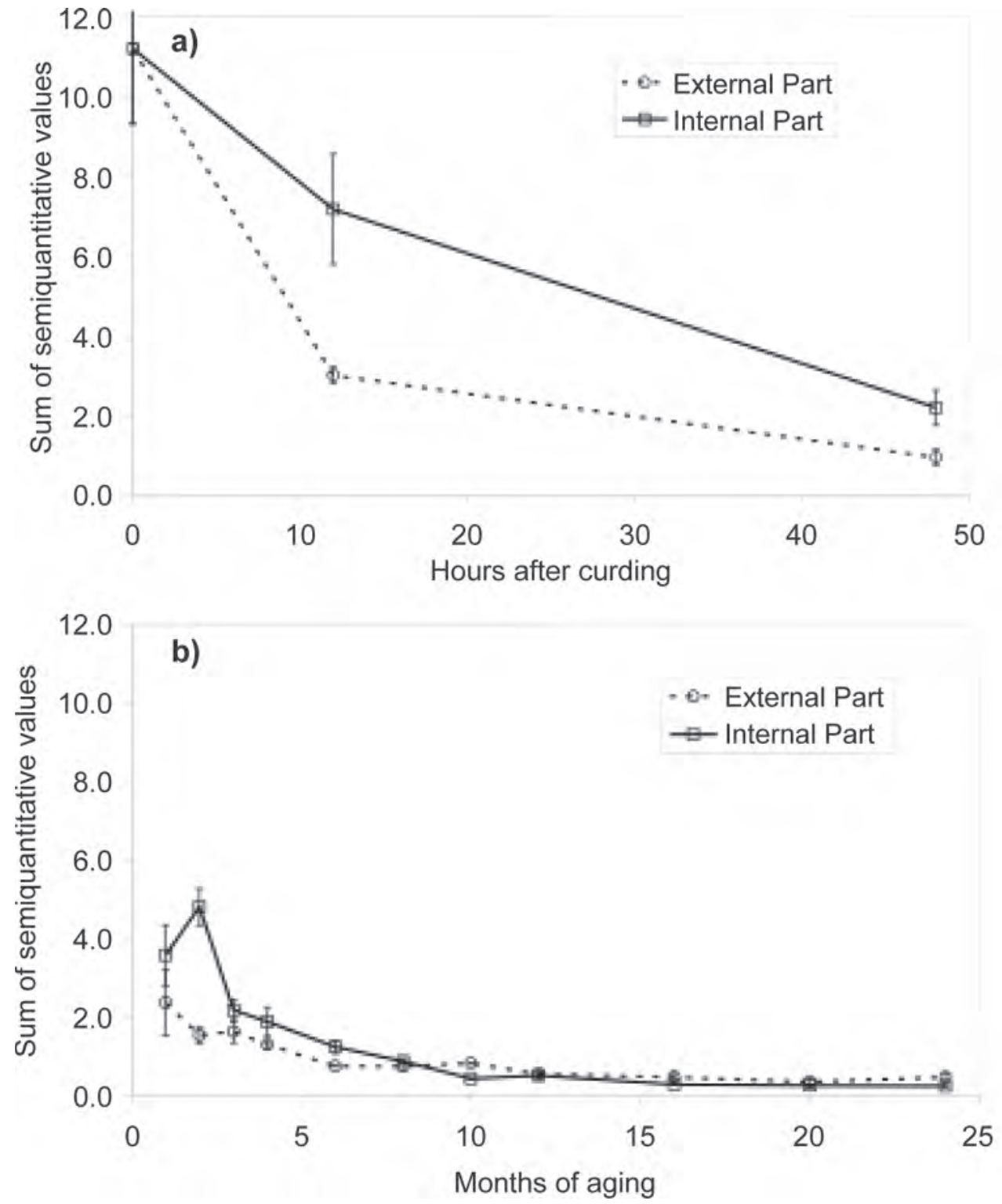

c)

$\alpha_{\mathrm{s} 1} \mathrm{CNf}(1-23)$

$\beta C N f(99-160)$

$\beta C N f(100-160)$

$\alpha_{\mathrm{S} 1} \mathrm{CNf}(24-34)$

$\alpha_{\mathrm{S} 1} \mathrm{CNf}(24-36)$

$\mathrm{a}_{\mathrm{S} 1} \mathrm{CNf}(24-38)$

$\beta \mathrm{CNf}(83-113)$

Not identified (MW 3132)

Not identified (MW 2747)

Figure 3. Evolution during cheese aging of peptides reaching the maximum amount during the first hours after curding. Total semiquantitative amounts (calculated as the sum of semiquantitative values of the peptides in this group) are reported up to $48 \mathrm{~h}$ after curding (a) and from mo 1 to 24 of aging (b), separately plotting the values corresponding to the internal and external parts of the wheel. The peptides characterizing this group are listed at the right side (c) in decreasing order of average chromatographic abundance. MW = molecular weight.

due to the simultaneous stop in their production and their degradation due to lysis of the starter culture, resulting in the release of intracellular peptidases. Peptide $\beta$ CNf(193-209) was the only peptide among all 53 peptides identified that, although peaking in the first month of aging, was present (in a discrete amount) from the start to the end of the aging period, indicating that its production, due either to residual coagulant activity or LAB proteases, continued throughout the ripening period.
Peptides reaching the maximum amount around mo 5 of aging characterized the third group, reported in Figure 5. These peptides are mostly phosphopeptides and derived mainly from the second group of peptides: $\beta \mathrm{CNf}(12-28) 4 \mathrm{P}, \beta \mathrm{CNf}(15-28) 4 \mathrm{P}, \beta-\mathrm{CNf}(15-28) 3 \mathrm{P}$, and $\beta-\mathrm{CNf}(11-28) 4 \mathrm{P}$ derive from the $\mathrm{N}$-terminal part of casein and all appear to be generated by cleavage at position 28-29, followed by N-terminal degradation, likely due to exopeptidases released in the medium after LAB cell death. In addition, $\beta-\mathrm{CNf}(57-93)$ was derived from 
a)

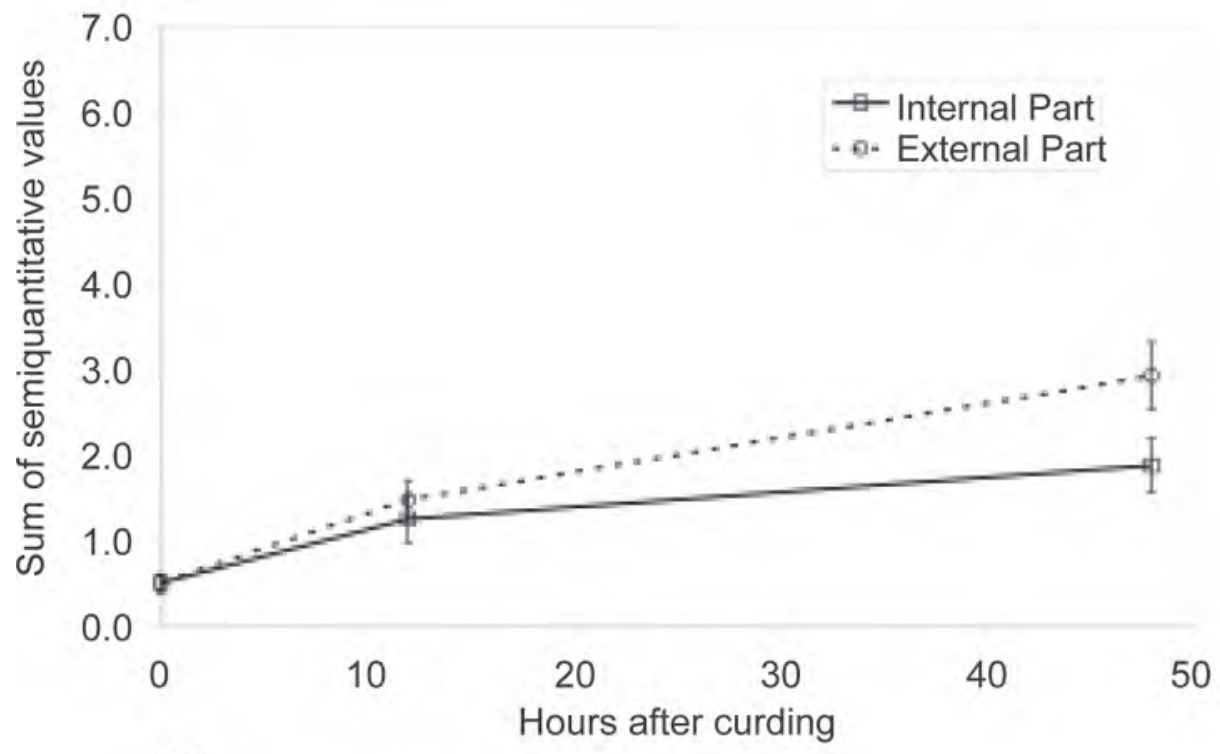

b)

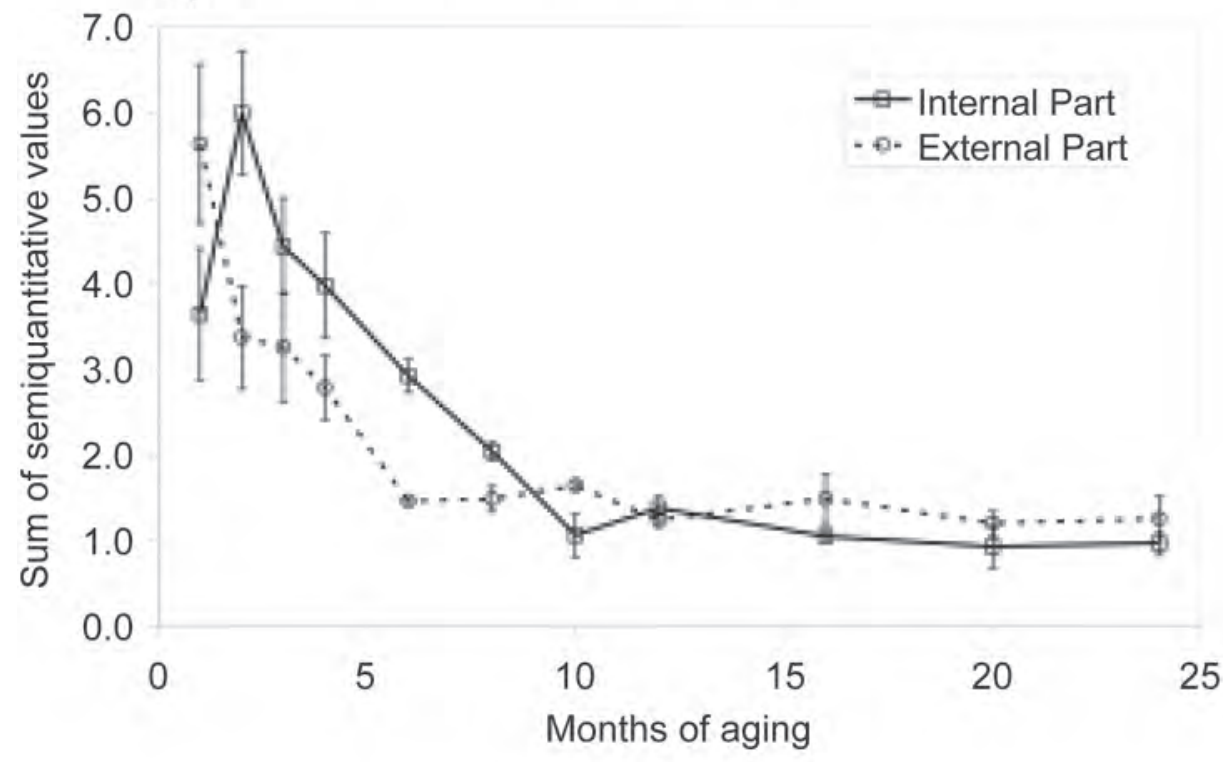

c)

$\alpha_{\mathrm{S} 1} \mathrm{CNf}(157-189)$

$\alpha_{\mathrm{S} 1} \mathrm{CNf}(157-188)$

$\beta C N f(193-209)$

$\alpha_{\mathrm{S} 1} \mathrm{CNf}(17-23)$

Not identified (MW 4064)

$\beta C N f(47-52)$

$\alpha_{\mathrm{S} 1} \mathrm{CNf}(10-14)$

$\beta C N f(7-29) 4 P$

$\beta C N f(53-93)$

$\alpha_{\mathrm{S} 1} \mathrm{CNf}(16-20)$

$\beta C N f(1-6)$

$\beta C N f(199-209)$

$\beta C N f(195-209)$

$\alpha_{\mathrm{S} 1} \mathrm{CNf}(1-17)$

$\beta C N f(103-119)$

$\alpha_{\mathrm{S} 1} \mathrm{CNf}(24-30)$

$\alpha_{\mathrm{S} 1} \mathrm{CNf}(1-13)$

$\beta C N f(194-209)$

$\alpha_{\mathrm{S} 1} \mathrm{CNf}(10-16)$

$\beta C N f(1-3)$

Figure 4. Evolution during cheese aging of peptides reaching the maximum amount at mo 1 to 2 of aging. Total semiquantitative amounts (calculated as the sum of semiquantitative values of the peptides in this group) are reported up to $48 \mathrm{~h}$ after curding (a) and from mo 1 to 24 of aging (b), separately plotting the values corresponding to the internal and external parts of the wheel. The peptides characterizing this group are listed at the right side (c) in decreasing order of average chromatographic abundance. $\mathrm{MW}=$ molecular weight.

$\beta-\mathrm{CNf}(53-93)$ after the cleavage of several AA from the N-terminal part. Interestingly, the production of peptides seemed to stop earlier in the external part of the wheel than in the internal part, which might be due to the progressively increasing salt concentration going from the external to the internal part, which could inhibit the endo- or exopeptidases responsible for peptide production.
This internal-external asymmetry in the development of peptides was even more evident in the fourth group, in which peptides reached the maximum amount around mo 6 of aging in the external part of the wheel but continued to increase in the internal part up to mo 10 of aging. Their data are shown in Figure 6, considering separately the first hours after curding (Figure 6a) and the rest of the aging time up to mo 


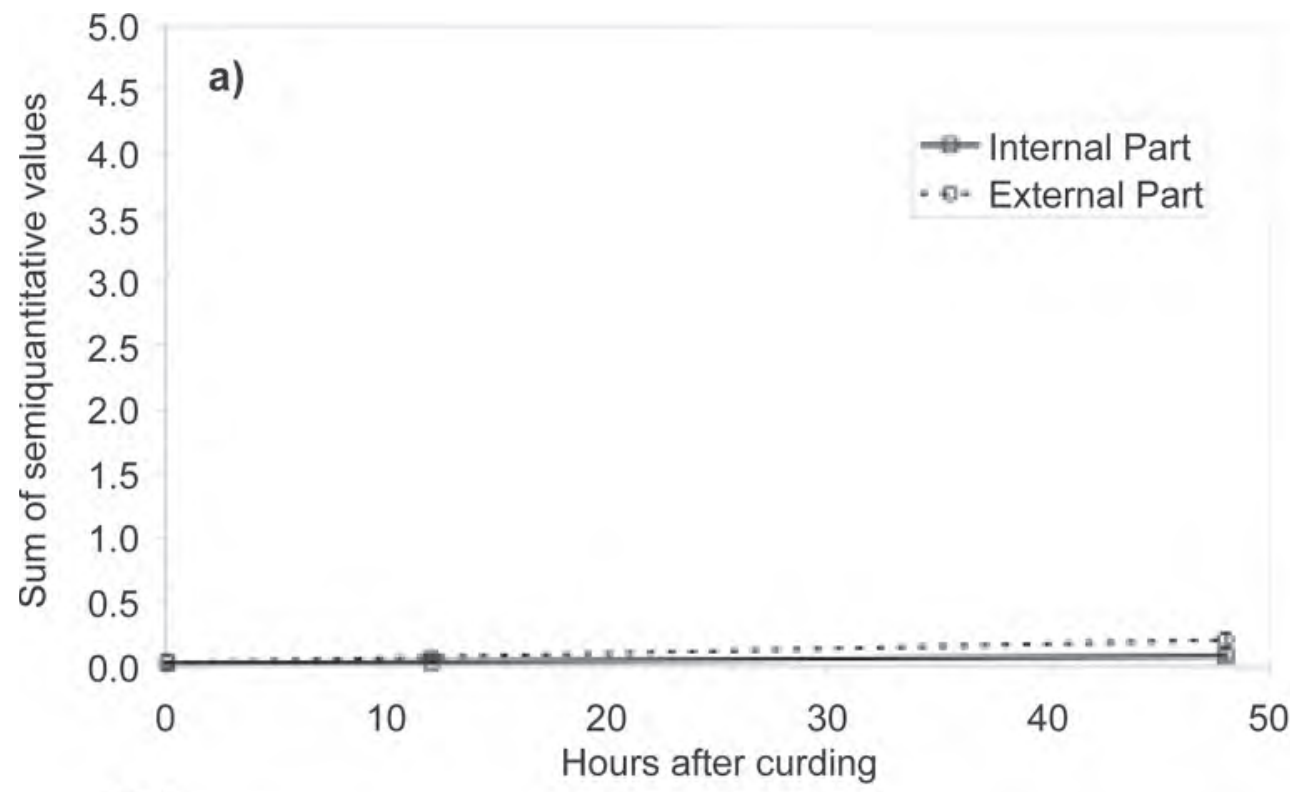

c)

$\beta C N f(12-28) 4 P$

$\beta C N f(15-28) 4 P$

$\beta C N f(15-28) 3 P$

$\beta C N f(94-107)$

$\beta C N f(11-28) 4 P$

$\beta C N f(57-93)$

Not identified (MW 2340)

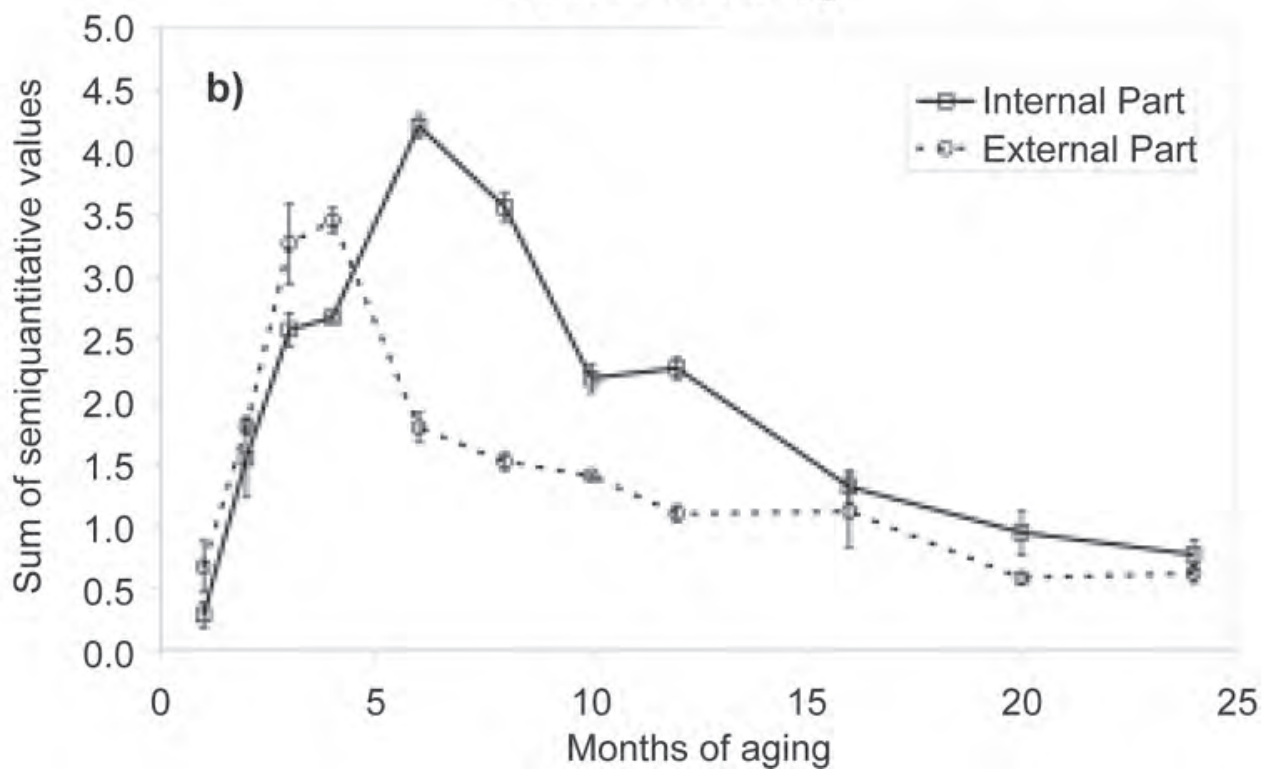

Figure 5. Evolution during cheese aging of peptides reaching the maximum amount at mo 5 of aging. Total semiquantitative amounts (calculated as the sum of semiquantitative values of the peptides in this group) are reported up to $48 \mathrm{~h}$ after curding (a) and from mo 1 to 24 of aging (b), separately plotting the values corresponding to the internal and external parts of the wheel. The peptides characterizing this group are listed at the right side (c) in decreasing order of average chromatographic abundance. MW = molecular weight.

24 (Figure 6b). Peptides belonging to this group are, again, listed in decreasing order of the intensity of the chromatographic signal in Figure 6c. These peptides were derived, through proteolytic events, from peptides already seen in the previous group as phosphopeptides: $\beta \mathrm{CNf}(16-28) 3 \mathrm{P}, \quad \beta \mathrm{CNf}(16-25) 3 \mathrm{P}, \quad \beta \mathrm{CNf}(14-28) 4 \mathrm{P}$, $\beta \mathrm{CNf}(13-28) 4 \mathrm{P}$, and $\beta \mathrm{CNf}(17-25) 2 \mathrm{P}$. Some of them seem to derive from the cleavage between positions 25 and 26 of $\beta-\mathrm{CN}$. It is interesting to notice that the $\mathrm{AA}$ at position 25 is the same as that present at position 28 (a lysine), thus implying a common enzymatic origin due to endopeptidases with a specificity for basic residues, which seems to be the dominant one at this time of aging. The prolonged production in the internal part, leading to a delayed and higher maximum amount, indicates, as before, that this environment was more suited to the enzymatic activity on account of the lower salt concentration.

The fifth and final group, characterized by a constant increase during aging up to mo 24, mainly comprised NPAD already reported in the literature (Sforza et al., 2009), mostly $\gamma$-glutamyl and lactoyl-amino acids (Fig- 


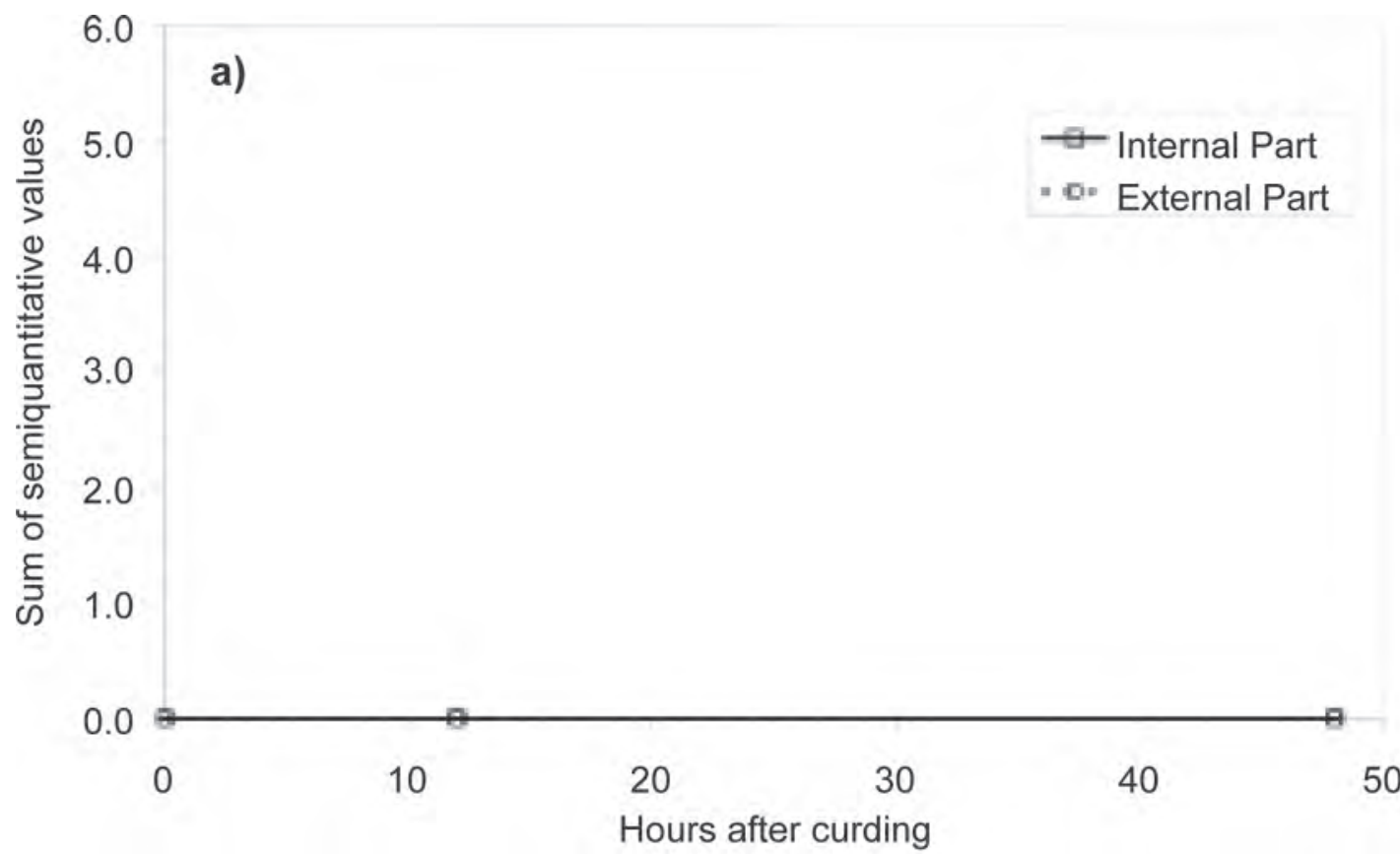

c)

$\beta C N f(16-28) 3 P$

$\beta C N f(16-25) 3 P$

$\beta C N f(14-28) 4 P$

$\beta C N f(13-28) 4 P$

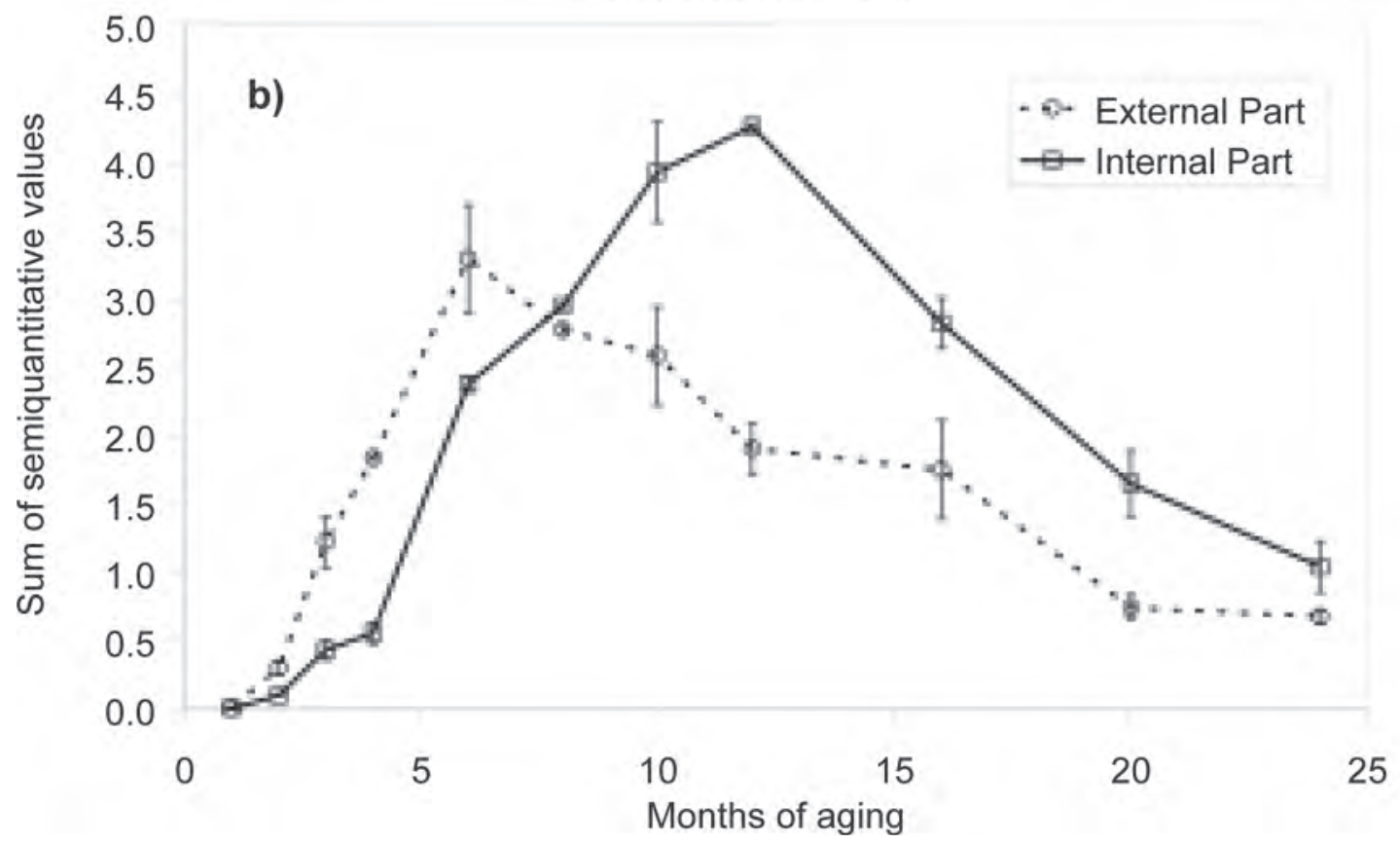

Figure 6. Evolution during cheese aging of peptides reaching the maximum amount at mo 6 to 10 of aging. Total semiquantitative amounts (calculated as the sum of semiquantitative values of the peptides in this group) are reported up to $48 \mathrm{~h}$ after curding (a) and from mo 1 to 24 of aging (b), separately plotting the values corresponding to the internal and external parts of the wheel. The peptides characterizing this group are listed at the right side (c) in decreasing order of average chromatographic abundance.

ure 7). Although the pathway of their production is still under investigation, data reported in the previous publication hint at a common enzymatic activity: the stereochemistry of the acyl group is always levorotatory (L-; although D-glutamic acid and D-lactic acid are present in Parmigiano-Reggiano cheese) and the AA used as acyl acceptor groups are always apolar (Phe,
Val, Leu, and Ile are the most abundant derivatives). The enzymatic systems involved are likely intracellular and released after LAB death. As evident in the current study, NPAD appeared to accumulate constantly during ripening (with a slight decrease in the accumulation rate in the last months of aging), likely due to their unusual structure, which partly prevented their degra- 
dation by other peptidases. This group also included several peptides arising from the central part of $\alpha_{\mathrm{s} 1}-\mathrm{CN}$ $\left[\alpha_{s 1} \mathrm{CN}(80-114)\right]$ and the products of its hydrolysis by an aminopeptidase, which have already been reported as characteristic of hard, long-aged cheeses (Sforza et al., 2003). Notably, the peptides of this group seemed to be evenly distributed in the internal and the external part of the wheels, indicating that the enzymes involved are not affected by the different environment and, in particular, by the different salt concentrations present in the different parts of the wheel.

\section{DISCUSSION}

The accumulation of a specific peptide always depends on a delicate balance between producing and degrading enzymes and the availability of the parent substrate. The total hydrolysis of the bond between positions 23 and 24 of $\alpha_{\mathrm{s} 1}$ CN by chymosin in the early stage of cheese production, for example, leads to a sudden increase in the concentration of the $\alpha_{\mathrm{s} 1} \mathrm{CN}(1-23)$ peptide, preventing its further production during aging, whereas subsequent degradation by bacterial proteinases decreases its amount, leading to the accumulation of shorter peptides derived from it. Subsequently, the increasing salt concentration during aging at a certain point inhibits the action of many endoproteases, blocking the degradation of the $\alpha_{\mathrm{s} 1}-\mathrm{CN}(1-23)$, which remains constant, and at the same time the exoproteases degrade the shorter peptides previously formed, which slowly disappear.

Most of the changes occur before mo 12 of aging, which is an important cross point for this kind of cheese, because only after this date can a wheel be sold in the market as an authentic Parmigiano-Reggiano cheese. However, as far as peptide composition is concerned, 12-, 18-, and 24-mo-old cheeses are different; therefore, this evolving character of the peptide fraction might be exploited, from an analytical point of view, for assessing the age of a cheese. Although such a study would imply analyzing many samples coming from different factories and produced at different times of the year, the data here reported at least indicate that such an evaluation is possible, and a similar approach on longer peptides has recently been reported in the literature for assessing aging time (Masotti et al., 2010).

Several known bioactive peptides (Phelan et al., 2009) were also found to be present in ParmigianoReggiano cheese samples, and for the first time, the month at which they are most present has been identified. As typical examples, $\alpha_{s 1} \mathrm{CN}(1-23)$, also known as isracidin, is known to have immunomodulatory effects (Lahov and Regelson, 1996); $\beta \mathrm{CN}(193-209)$ is also im- munomodulatory and has been recently demonstrated to be internalized intact by cells (Regazzo et al., 2010). On the other hand, phosphopeptides derived from the N-terminal part of $\beta$-CN are known for their mineralbinding capacity and vehiculation activity (Ferraretto et al., 2001), and they are mostly present at more advanced aging times, some of them reaching a maximum concentration in 16-mo-old cheese.

Aged cheeses show a consistent presence of NPAD. Having been relatively recently reported, their biological activity is mostly unknown, but given their consistent presence in aged cheeses (up to $50 \mathrm{mg} / 100 \mathrm{~g}$ of cheese; Sforza et al., 2009), further studies aimed at evaluating their bioactive potential now seem necessary. Future studies will necessarily clarify if these potentially bioactive peptides are present at pharmacologically relevant doses, a necessary prerequisite for demonstrating eventual bioactivity. Several NPAD and, in particular, $\gamma$-Glu-Phe, have also been reported to positively affect the sensory characteristic of other cheeses (Toelstede et al., 2009) and may be involved in imparting the characteristic pleasant flavor to aged hams (Sforza et al., 2006). The consistent presence of NPAD in aged cheeses indicates that the biochemical process responsible for their production, which is clearly not a proteolytic event, is an important phenomenon for determining cheese quality. Being that this biochemical reaction is almost as important as proteolysis itself in determining the peptide composition of aged cheese, it will need to be more thoroughly studied in the future.

Last, the changing peptide pattern is the direct result of the changing enzymatic activities occurring inside the cheeses during aging, which, in turn, are also related to the microbiological composition. It has recently been reported, on the same cheese samples of the present work, that around mo 10 of aging, the dominant microbiota in Parmigiano-Reggiano cheese, initially mainly constituted by starter Lactobacillus helveticus, gradually switches to nonstarter Lactobacillus rhamnosus (Gatti et al., 2008). Interestingly, around these months, a drastic change in peptide composition is observed, with the appearance of new peptides, mostly due to cleavages at basic residues of $\beta$-CN, followed by hydrolysis by an aminopeptidase. It is tempting to speculate that the new peptides observed are directly linked to the new dominant microbiota or to the enzymes released by the death of the previous one, thus indicating a direct influence of the microbiological composition on the molecular content, which, in turn, is related to flavor, texture, and functional properties. Further studies will be required to link the 2 issues and expand all of these observations to Parmigiano-Reggiano whole production. 


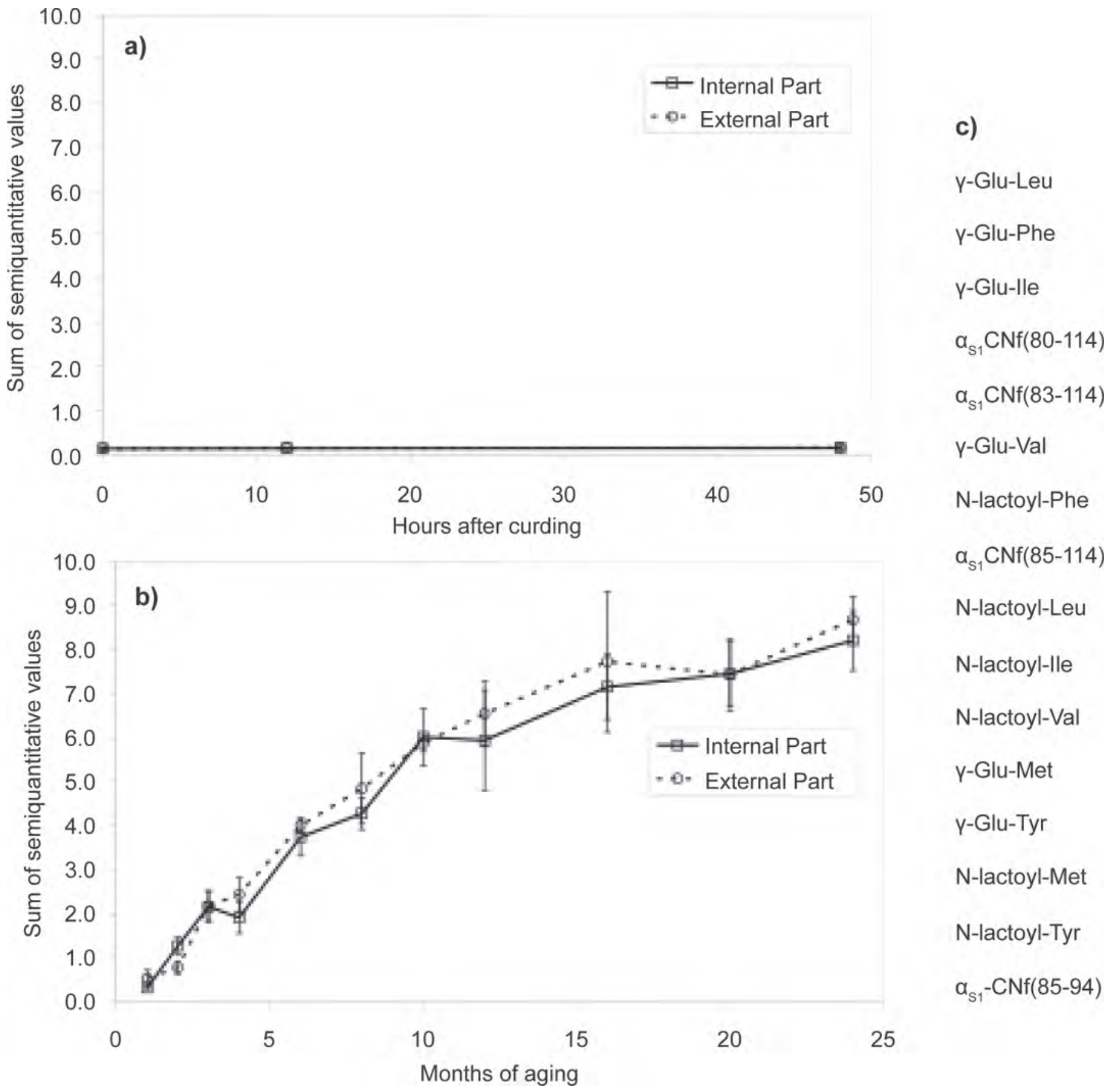

Figure 7. Evolution during cheese aging of peptides continuously increasing during aging time. Total semiquantitative amounts (calculated as the sum of semiquantitative values of the peptides in this group) are reported up to $48 \mathrm{~h}$ after curding (a) and from mo 1 to 24 of aging (b), separately plotting the values corresponding to the internal and external parts of the wheel. The peptides characterizing this group are listed at the right side (c) in decreasing order of average chromatographic abundance.

\section{CONCLUSIONS}

According to the results obtained in the present work, the peptide fraction of Parmigiano-Reggiano cheese is constantly evolving during aging. Peptide production and degradation during aging is a very complex process controlled by many different enzymes. These biochemical events result in peptides that are the substrates for further processing to shorter peptides and free AA. This study represents the first detailed picture of the 
evolution of the oligopeptide fraction in ParmigianoReggiano cheese, outlining its strict correlation with aging time and the microbiota present in the cheese.

\section{ACKNOWLEDGMENTS}

This work was performed thanks to a grant from the Emilia-Romagna Region (Italy), in collaboration with the Consorzio del Parmigiano Reggiano.

\section{REFERENCES}

Addeo, F., L. Chianese, R. Sacchi, S. S. Musso, P. Ferranti, and A. Malorni. 1994. Characterization of the oligopeptides of Parmigiano-Reggiano cheese soluble in $120 \mathrm{~g}$ trichloroacetic acid/l. J. Dairy Res. 61:365-374.

Addeo, F., L. Chianese, A. Salzano, R. Sacchi, U. Cappuccio, P. Ferranti, and A. Malorni. 1992. Characterization of the $12 \%$ trichloroacetic acid-insoluble oligopeptides of Parmigiano-Reggiano cheese. J. Dairy Res. 59:401-411.

Bottari, B., M. Santarelli, E. Neviani, and M. Gatti. 2010. Natural whey starter for Parmigiano Reggiano: Culture-independent approach. J. Appl. Microbiol. 108:1676-1684.

Broadbent, J. R., M. Strickland, B. C. Weimer, M. E. Johnson, and J. L. Steele. 1998. Peptide accumulation and bitterness in Cheddar cheese made using single-strain Lactococcus lactis starters with distinct proteinase specificities. J. Dairy Sci. 81:327-337.

Ferranti, P., F. Barone, L. Chianese, F. Addeo, A. Scaloni, L. Pellegrino, and P. Resmini. 1997a. Phosphopeptides from Grana Padano cheese: Nature, origin and changes during ripening. J. Dairy Res. 64:601-615.

Ferranti, P., E. Itolli, F. Barone, A. Malorni, G. Garro, P. Laezza, L. Chianese, F. Migliaccio, V. Stingo, and F. Addeo. 1997b. Combined high resolution chromatographic techniques (FPLC and HPLC) and mass spectrometry-based identification of peptides and proteins in Grana Padano Cheese. Lait 77:683-697.

Ferraretto, A., A. Signorile, C. Gravaghi, A. Fiorilli, and G. Tettamanti. 2001. Casein phosphopeptides influence calcium uptake by cultured human intestinal HT-29 tumor cells. J. Nutr. 131:16551661.

Fox, P. F. 1999. Cheese varieties ripened in brine. Page 229 in Cheese: Chemistry, Physics and Microbiology. Volume 2: Major Cheese Groups. Aspen Publishers, New York, NY.

Fox, P. F., and P. L. H. McSweeney. 1996. Proteolysis in cheese during ripening. Food Rev. Int. 12:457-509.

Gatti, M., J. De Dea Lindner, A. De Lorentiis, B. Bottari, M. Santarelli, V. Bernini, and E. Neviani. 2008. Dynamics of whole and lysed bacterial cells during Parmigiano-Reggiano cheese production and ripening. Appl. Environ. Microbiol. 74:6161-6167.

Jensen, M. P., F. K. Vogensen, and Y. Ardö. 2009. Variation in caseinolytic properties of six cheese related Lactobacillus helveticus strains. Int. Dairy J. 19:661-668.

Lahov, E., and W. Regelson. 1996. Antibacterial and immunostimulating casein-derived substances from milk: Casecidin, isracidin peptides. Food Chem. Toxicol. 34:131-145.

Masotti, F., J. A. Hogenboom, V. Rosi, I. De Noni, and L. Pellegrino. 2010. Proteolysis indices related to cheese ripening and typicalness in PDO Grana Padano cheese. Int. Dairy J. 20:352-359.

McSweeney, P. L. H. 2004. Biochemistry of cheese ripening. Int. J. Dairy Technol. 57:127-144.

McSweeney, P. L. H., N. F. Olson, P. F. Fox, A. Healy, and P. Højrup. 1993. Proteolytic specificity of casein on bovine $\alpha_{\mathrm{s} 1}$-casein. J Dairy Res. 60:401-412.

Phelan, M., A. Aherne, R. J. FitzGerald, and N. M. O'Brien. 2009. Casein-derived bioactive peptides: Biological effects, industrial uses, safety aspects and regulatory status. Int. Dairy J. 19:643-654.

Piraino, P., V. K. Upadhyay, R. Rossano, P. Riccio, E. Parente, A. L. Kelly, and P. L. H. McSweeney. 2007. Use of mass spectrometry to characterize proteolysis in cheese. Food Chem. 101:964-972.

Regazzo, D., D. Molle, G. Gabai, D. Tome, D. Dupont, J. Leonil, and R. Boutrou. 2010. The (193-209) 17-residues peptide of bovine $\beta$-casein is transported through Caco-2 monolayer. Mol. Nutr. Food Res. 54:1428-1435.

Sforza, S., V. Cavatorta, G. Galaverna, A. Dossena, and R. Marchelli. 2009. Accumulation of non-proteolytic aminoacyl derivatives in Parmigiano-Reggiano cheese during ripening. Int. Dairy J. 19:582-587.

Sforza, S., L. Ferroni, G. Galaverna, A. Dossena, and R. Marchelli. 2003. Extraction, semi-quantification, and fast on-line identification of oligopeptides in Grana Padano cheese by HPLC-MS. J. Agric. Food Chem. 51:2130-2135.

Sforza, S., G. Galaverna, A. Dossena, R. Marchelli, and E. Neviani., andPinelli, C. 2004. Study of the oligopeptide fraction in Grana Padano and Parmigiano-Reggiano cheeses by liquid chromatography-electrospray ionization mass spectrometry. Eur. J. Mass Spectrom. (Chichester, Eng.) 10:421-427.

Sforza, S., G. Galaverna, C. Schivazappa, R. Marchelli, A. Dossena and R. Virgili. 2006. Effect of extended aging of Parma dry-cured ham on the content of oligopeptides and free amino acids. J. Agric. Food Chem. 54:9422-9429.

Sousa, M. J., Y. Ardö, and P. L. H. McSweeney. 2001. Advances in the study of proteolysis during cheese ripening. Int. Dairy J. 11:327-345.

Toelstede, S., A. Dunkel, and T. Hofmann. 2009. A series of kokumi peptides impart the long-lasting mouthfulness of matured Gouda cheese. J. Agric. Food Chem. 57:1440-1448 